\title{
An audit of drug package insert: a survey based study in India
}

\author{
Priyanka P. Hotha*, Purvi J. Tanna
}

Department of Pharmacology, Shri M. P. Shah Govt. Medical College, Jamnagar, Gujarat, India

Received: 04 September 2016

Accepted: 12 October 2016

*Correspondence to:

Dr. Priyanka P. Hotha,

Email:

priyankahotha@gmail.com

Copyright: (C) the author(s), publisher and licensee Medip Academy. This is an openaccess article distributed under the terms of the Creative Commons Attribution NonCommercial License, which permits unrestricted noncommercial use, distribution, and reproduction in any medium, provided the original work is properly cited.

\begin{abstract}
Background: The primary source of drug information is a Package Insert. It is a printed leaflet that contains information based on regulatory guidelines for the safe and effective use of a drug. It is also known as prescription drug label or prescribing information. Regulatory requirements for drug package inserts or leaflets vary across nations. United States-Food and Drug Administration (USFDA) and European Medicines Agency (EMA) amend their regulations governing the content and format of labelling for drug products from time to time. US-FDA has published a revised guideline in the Federal Register of January 2006, which is being followed by pharmaceutical industry of the country.

Methods: Around 192 package inserts were collected from pharmacies located at different areas. They were analyzed according to Sections 6.2 and 6.3 of Schedule D of Drugs and Cosmetics Rules, 1945.

Results: Out of 192 package inserts, most available information in therapeutic indications is Posology and method of administration (97.3\%) followed by Contra-indications $(93.2 \%)$ in pharmaceutical information, it is Special precautions for storage $(77 \%)$ followed by Shelf life in the medical product as packaged for sale $(33.8 \%)$.

Conclusions: Contents of the package inserts should be complete, reliable and up to date. This can be a step forward for ethical and effective dissemination of healthcare services in our growing society. Therefore, recommended to update the existing package inserts based on criteria mentioned in the Schedule D of Drug and Cosmetic Act, 1945.
\end{abstract}

Keywords: India, Packet inserts, Pharmaceutical information, Therapeutic indications

\section{INTRODUCTION}

Drug labelling refers to all of the printed information that accompanies a drug, including the label, the wrapping and the package insert. ${ }^{1}$ Accurate and reliable drug information is essential for safe and effective use of marketed products. The primary source of drug information is a Package Insert (PI). It is a printed leaflet that contains information based on regulatory guidelines for the safe and effective use of a drug. It is also known as prescription drug label or prescribing information.

A good PI contains the approved, essential, and accurate information about a drug. It is written in a language that is not promotional, false, or misleading. It is evidence based and is updated time to time as relevant preclinical and clinical data becomes available. ${ }^{2}$ This drug product information commences early during the developmental phase of a pharmaceutical product with careful scrutiny of available information. ${ }^{3}$ Regulatory requirements for drug package inserts or leaflets vary across nations. United States-Food and Drug Administration (US-FDA) and European Medicines Agency (EMA) amend their regulations governing the content and format of labelling for drug products from time to time. ${ }^{3,4}$ US-FDA has published a revised guideline in the Federal Register of January 2006, which is being followed by pharmaceutical industry of the country. ${ }^{3}$

As per Directive 2001/83/EC of the European Parliament and of the Council of 6 November 2001, medicinal products must be accompanied by package leaflet. It also emphasizes that the package leaflet must be written and designed to be clear and understandable, enabling the users to act appropriately. Also, the directive states that 
package leaflet must be clearly legible in the official language or languages of the Member State(s) in which the medicinal product is placed on the market. ${ }^{4}$

In India, the concept of package insert is governed by the 'Drugs and Cosmetics Act (1940) and Rules (1945). The section 6 of Schedule D (II) of the rules lists the headings according to which information should be provided in the PIs.

The 'Section 6.2' mandates that the PIs must be in 'English' and provides information regarding the specific requirements. The 'Section 6.3' mandates pharmaceutical information on list of excipients.

The present study will undertake to evaluate the quality and contents of drug package inserts approved by Central Drugs Standard Control Organization (CDSCO; Drug regulatory body of India).

Aim of the study was described as:

1. Reviewed the information available in drug package inserts of India and assessed the improvement over last few years.

2. Provide information which is essential for the safe and effective use of the drugs, and hence reducing the number of adverse reactions resulting from medication errors.

Objectives of the study was to ensure the conformance of package inserts with the Indian regulatory guidelines in terms of drug information and whether there is any improvement over last few years.

\section{METHODS}

It was survey based and observational type of study.

\section{Source of data}

Leaflets of drug products were collected from pharmacy stores located in the region.

Duration of the study was from January 2015 to April 2015.

This was survey-based study to evaluate leaflets that was supplied along with allopathic drug products marketed by pharmaceutical companies in India. The survey was conducted over a period from January 2015 to April 2015. Leaflets of drug products were collected from pharmacy stores located in the region. The package inserts were analyzed for the presentation and completeness of clinical and pharmaceutical information as mentioned. The clinical information included in the package inserts was analyzed according to Sections 6.2 and 6.3 of Schedule D of Drugs and Cosmetics Rules, 1945 .

\section{Labelling and packaging information of drugs}

Labels should confirm as per the specifications under the Drugs and Cosmetics Rules 1945.

Package insert should be in English and shall indicate the following therapeutic indications.

- Posology and method of administration

- Contra-indications

- Special warnings and special precautions for use, if any

- Interaction with other medicaments and other forms of interaction

- $\quad$ Pregnancy and lactation, if contra-indicated

- Effects on ability to drive and use machines, if contra-indicated

- Undesirable effects/side effects

- $\quad$ Antidote for overdosing.

Package insert should indicate the following pharmaceutical information.

- List of excipients

- Incompatibilities

- Shelf life in the medical product as packaged for sale

- $\quad$ Shelf life after dilution or reconstitution according to direction

- Shelf life after first opening the container

- Special precautions for storage

- Nature and specification of the container

- Instructions for use/handling.

The package inserts was checked for the presence of the headings mentioned in Section 6.2 and 6.3. If a heading was not present in a package insert, the entire insert was checked for the presence or absence of information relevant to the concerned heading. The information was present under the relevant heading or elsewhere in the package insert it was scored as one, otherwise a score of zero was assigned. After each of the selected package inserts was scored, the total scores for each heading was calculated by totalling the scores from individual package inserts. The total scores were expressed as absolute numbers and percentages.

\section{RESULTS}

Total 192 package inserts were evaluated in this study. Among them total 124 oral, 31 injectable, and 37 topical preparations marketed by 20 different pharmaceutical companies in India. Out of them, 181 were from Indian companies and 11 from multinational companies. The clinical information included in the package inserts was analyzed according to Sections 6.2 and 6.3 of Schedule D of Drugs and Cosmetics Rules, 1945. The package inserts were checked for the presence of the headings mentioned in Section 6.2 and 6.3 (Table 1). None of the reviewed 
inserts contained all sections as required by the Drugs and Cosmetics Act.

\section{Table 1: Results of package inserts contain therapeutic indication.}

\begin{tabular}{|lll|}
\hline $\begin{array}{l}\text { Therapeutic } \\
\text { indication }\end{array}$ & $\begin{array}{l}\text { Sum of } \\
\text { positive score } \\
\text { [no }(\%)]\end{array}$ & $\begin{array}{l}\text { Sum of } \\
\text { negative score } \\
\text { [no (\%)] }\end{array}$ \\
\hline $\begin{array}{l}\text { Posology and } \\
\text { method of } \\
\text { administration }\end{array}$ & $187(97.3 \%)$ & $05(2.6 \%)$ \\
\hline Contra-indications & $179(93.2 \%)$ & $13(6.7 \%)$ \\
\hline $\begin{array}{l}\text { Special warnings } \\
\text { and special } \\
\text { precautions for } \\
\text { use, if any }\end{array}$ & $175(91.1 \%)$ & $17(8.8 \%)$ \\
\hline $\begin{array}{l}\text { Interaction with } \\
\text { other medicaments } \\
\text { and other forms of } \\
\text { interaction }\end{array}$ & $149(77.6 \%)$ & $43(22.3 \%)$ \\
\hline $\begin{array}{l}\text { Pregnancy and } \\
\text { lactation, if contra- } \\
\text { indicated }\end{array}$ & $148(77 \%)$ & $44(22.9 \%)$ \\
\hline $\begin{array}{l}\text { Effects on ability } \\
\text { to drive and use } \\
\text { machines, if } \\
\text { contra-indicated }\end{array}$ & $36(18.7 \%)$ & $156(81.2 \%)$ \\
\hline $\begin{array}{l}\text { Undesirable } \\
\text { effects/side effects }\end{array}$ & $167(86.9 \%)$ & $25(13 \%)$ \\
\hline $\begin{array}{l}\text { Antidote for } \\
\text { overdosing }\end{array}$ & $100(52 \%)$ & $92(47.9 \%)$ \\
\hline
\end{tabular}

Table 2: Results of package inserts contain pharmaceutical information.

\begin{tabular}{|lll|}
\hline $\begin{array}{l}\text { Pharmaceutical } \\
\text { information }\end{array}$ & $\begin{array}{l}\text { Sum of } \\
\text { positive score } \\
{[\text { no }(\%)]}\end{array}$ & $\begin{array}{l}\text { Sum of } \\
\text { negative score } \\
{[\text { no }(\%)]}\end{array}$ \\
\hline List of excipients & $20(10.4 \%)$ & $172(89.5 \%)$ \\
\hline Incompatibilities & $50(26 \%)$ & $142(73.9 \%)$ \\
\hline $\begin{array}{l}\text { Shelf life in the } \\
\text { medical product as } \\
\text { packaged for sale }\end{array}$ & $65(33.8 \%)$ & $127(66.1 \%)$ \\
\hline $\begin{array}{l}\text { Shelf life after } \\
\text { dilution or } \\
\text { reconstitution } \\
\text { according to } \\
\text { direction }\end{array}$ & $06(3.1 \%)$ & $186(96.8 \%)$ \\
\hline $\begin{array}{l}\text { Shelf life after first } \\
\text { opening the } \\
\text { container }\end{array}$ & $09(4.6 \%)$ & $183(95.3 \%)$ \\
\hline $\begin{array}{l}\text { Special precautions } \\
\text { for storage }\end{array}$ & $148(77 \%)$ & $44(22.9 \%)$ \\
\hline $\begin{array}{l}\text { Nature and } \\
\text { specification of the } \\
\text { container }\end{array}$ & $21(10.9 \%)$ & $171(89 \%)$ \\
\hline $\begin{array}{l}\text { Instructions for } \\
\text { use/handling }\end{array}$ & $48(25 \%)$ & $144(75 \%)$ \\
\hline
\end{tabular}

\section{DISCUSSION}

As package inserts are one of the most frequently used sources of written drug information, approaches to optimise them should be explored as soon as possible. This especially refers to difficulties in understanding the extensive information provided, and suggests a more suitable structure for package inserts. Package inserts should contain only the information that is of paramount importance for the patient, although this is debatable from a legal point of view. ${ }^{6}$ Although there is an improvement in the quality and content of Indian package inserts over time, but still there are areas which remain unaddressed. It is important to realise that, apart from prescriber and pharmacist, patients are also end users of package insert. Currently in India, the structure and content of the information on the inserts is geared towards prescribers only. Given the fact that unauthorized over-the-counter drug dispensing is a prevalent practice in India, and that patient education is in infant stages, there is a need for package inserts to be more patientfriendly and specifically designed to avoid medication errors. $^{7}$ This can be achieved by conducting regular surveys to model the package inserts for the population. There are many examples of such surveys done in developed countries with an aim to improve the package insert and make them user friendly for patients. ${ }^{7}$ From the above findings, it is suggested that the package inserts must be optimized and tested by selected groups of experts prior to the approval of the drug. This will ensure the avoidance of the lack of information and will guide towards informed and better treatment outcomes. The supply of the package inserts should be made mandatory in the package along with the drugs. The government should make strict rules to ensure that the pharmaceutical companies comply with the regulatory guidelines.

\section{CONCLUSION}

The package insert is a good source of information in addition to instructions your doctor may give you. It's a good idea to review the package insert for any new medicine you take. That's why contents of package inserts should be complete, reliable, and up to date. This can be a step forward for ethical and effective dissemination of healthcare services in our growing society. Therefore, recommended to update the existing package inserts based on criteria mentioned in the Schedule D of Drug and Cosmetic Act, 1945.

\section{ACKNOWLEDGEMENTS}

Authors are acknowledging Institutional Ethics Committee for approval and Head of Department and Faculties of Department of Psychiatry and pharmacology, MPSMC, Jamnagar for providing support and facilities.

Funding: No funding sources

Conflict of interest: None declared 
Ethical approval: The study was approved by the Institutional Ethics Committee

\section{REFERENCES}

1. Srivastava B, Prakash C, Sinha AK. Errors in Drug Labeling and Medico-Legal Awareness. J Indian Acad Forensic Med. 2011;32(3):228-30.

2. Ved JK. Package Inserts in India: Need for a Revision. J International Phar Scie and Res. 2010;1(11):454-56.

3. Food and Drug Administration, HHS. Requirements on content and format of labeling for human prescription drug and biological products. Fed Reg. 2006;71:3921-97.

4. European Medicines Agency. Guideline on the Packaging Information of Medicinal Products for Human Use Authorized by the Community; 2008. Available http://ec.europa.eu/enterprise/pharmaceuticals/eudral ex/vol-2/c/bluebox_02_2008.pdf. [Accessed July12, 2012]

5. The Drugs and Cosmetics Act and Rules. Ministry of Health and Family Welfare, Government of India; 2003:312. Available from: http://cdsco.nic.in/html/copy \%20of\%201.\%20d and cact121.pdf. Accessed on March 15,2013.

6. Kaikade SB, Jha RK. Assessment of Awareness and Attitude towards Package Inserts Amongst Rural Population, Res J of Pharmaceutical, Biological and Chemical Sciences. 2011;2(4):982.

7. Kalam A, Anwar S, Fatima A, Drug package inserts in india: current scenario, World J Pharmacy and Pharmaceutical Sci. 2014;3(4):385-92.

Cite this article as: Hotha PP, Tanna PT. An audit of drug package insert: a survey based study in India. Int J Basic Clin Pharmacol 2017;6:629-32. 